\title{
3 EMI for information engineering students
}

\author{
A case study
}

Sally Chen and Shou-De Lin

\section{Introduction}

The use of foreign or second languages as a medium of instruction has become widespread in the past decade. The adoption of English-medium instruction (EMI), in particular, reflects the drastic expansion of this global language into education.

Modern EMI is usually traced back to Content and Language Integrated Learning (CLIL), but in fact, the definition of EMI goes beyond that of CLIL (Tu \& Burns, 2014). CLIL originally targeted the middle school level, with language treated as part of the course. Thus, CLIL teachers were responsible for the delivery of both content knowledge and language competence. EMI, on the other hand, uses English language as a tool for acquiring knowledge of a certain discipline, and has been adopted in all levels of education (Dearden, 2014).

The switch to the use of EMI also reflects a change in the approach of language teaching in higher education. Regarding this, EMI should not be confused with English for Specific Purposes (ESP) or English for Academic Purposes (EAP). EAP differs from ESP in that it aims to help students learn those aspects of English that are necessary for future study or work in English medium higher education. Teachers of ESP programs are mainly responsible for teaching the English language, while the content of their teaching materials is related to one certain discipline. For example, ESP in engineering education focuses on teaching the terminology and communication skills required for the engineering field (Cheremissina \& Riemer, 2001). Thus, the two should be differentiated from EMI, in which there is an expected connection between the English language itself and high levels of knowledge in a particular academic field (Shohamy, 2012).

Recently, Hüttner (2019) has proposed the new term "disciplinary language," to better capture the concept of EMI. The term refers to accessing disciplinary knowledge through the English language, and the learning of this subject-specific language is accomplished via the process of active and repetitive practice (p. 10). In this way, EMI can further be distinguished from ESP 
in that it not only includes the training of general English skills for students of a specific field, but facilitates their use of English as a tool in order to obtain expertise in a particular field.

EMI has been growing globally in all stages of education (Dearden, 2014), driven by economic, social, political, and educational forces. Specifically, "English-medium instruction has become commonplace in many institutes of higher education in countries where English is not the native language" (Wilkinson, 2013, p. 3). For example, following a similar growth pattern to that seen in Europe, sharp rises in the use of EMI have been observed in higher education in Middle Eastern and Asian countries (Macaro et al.,2018).

Given that globalization is an irreversible trend, EMI has been adopted by various professional fields, including engineering. In one study applying EMI in engineering, faculty members of the engineering departments in Turkish universities agreed that EMI allows students to make better use of their expertise due to constant contact with resources provided in English. However, these lecturers also admitted that their students were not proficient enough to learn subject matter in this global language. Thus, the idea of lecturing in Turkish, the students' first language (L1), was believed to be an alternative, providing the students with a clearer understanding of the course content (Basibek et al., 2014). In another study, three major engineering universities in Korea were chosen to examine students' perceptions of EMI and L1 use in EMI classes. A questionnaire-based survey was conducted among undergraduate students of the universities, and the results showed that students in general felt that their English ability was insufficient. The majority of the students preferred Korean-medium instruction over EMI, and did not find EMI improved their English ability. (Kim et al., 2017). The fact that engineering students in Korea were not proficient enough in English was supported by another questionnaire-based study, which looked at professors from various departments in a Korean engineering school. Moreover, it was not only the students but also the professors themselves who were in need of intensive language training to provide adequate EMI courses (Kim, 2014).

In Taiwan, a survey investigating 157 students at a university of science and technology showed that while local students were motivated by the potential benefit of EMI on their English ability, their major learning anxiety came from self-evaluated low English proficiency. In the same study, some participants suggested, in the interview following the survey, that instructors use Chinese translation to assist in EMI course teaching (Huang, 2015).

In a recent study on Korean engineering professors, most professors recognized the dual problems of students' insufficient English proficiency, and lack of English lecturing skills among Korean national faculty members in leading EMI classes (Kim et al., 2017). It is likely that this lack of training contributes to the current situation in which, despite the majority of university professors speaking English, some are unable to deliver courses effectively in English. (Dearden, 2014). 
To respond to this, two pedagogical strategies, team teaching (Doiz et al., 2012) and translanguaging (García, 2009; García \& Li, 2014), have been introduced so as to tackle the language issues, whether they result from an imbalance in the English proficiency level of the students or from a lack of experience in lecturing in English on the part of the content teachers. As already mentioned, in EMI, English is considered a tool to help students acquire the expertise of a given discipline. To lessen the burden of the content teacher, it is possible to form a cooperative work unit with a language teacher (Lasagabaster, 2018), thus shifting the responsibility for instruction from the individual to the team. The language issues can be further tackled by incorporating the concept of translanguaging into EMI pedagogy. Originating from Welsh, the term translanguaging is increasingly used in bilingual education to refer to the process by which teachers and students engage in "multiple discursive practices...in order to make sense of their bilingual worlds" (García, 2009 , p. 45). With its distinctive conception of the heteroglossic and dynamic nature of bilingualism, translanguaging echoes the viewpoint expressed by many EMI researchers that for EMI instruction in an English as a foreign language context, L1 and English can be used alternately to serve different pedagogical functions. For example, a study on the local and international students' feedback on the EMI classes at two second-tier private universities in Japan showed that use of Japanese (L1) in class, either by way of translated documents or concise explanations, better facilitated class activities for the local students (Chapple, 2015).

EMI is relatively new to higher education in Taiwan, as the development of EMI at universities has been observed in the Asia-Pacific region only over the past two decades (Chin \& Li, Chapter 1). The idea was first realized in the region during the early 2000 s when a small number of elite public universities started to offer business degrees taught in English, such as global or international MBA programs. More and more EMI courses have appeared since then. For instance, during the 2005-2006 academic year, there were 420 EMI courses offered by a top ranking public university in northern Taiwan (Wu, 2006). However, exactly how EMI is implemented in the engineering field in Taiwan remains unexamined. In this chapter, the structure and the design of a real case will be reported.

Different from most Asian countries, in which EMI policies have been enacted by their governments, in the beginning, the implementation of EMI in Taiwan appeared to be more voluntary, that is, "without having any policy imposed on them by the education bureaus" (Yang, 2015). Given that there were no fixed rules for implementation back then, universities in Taiwan used various ways to encourage their faculty members to offer more EMI courses, as English-medium classes require much more time for preparation and professors were reluctant to take on the extra burden unprompted. For instance, one university offered $50 \%$ extra credit hours as a financial incentive for its faculty members to offer EMI classes (Wu, 2006). 
Recently, sponsorship has been offered by the Ministry of Education in Taiwan to encourage EMI in higher education. For example, faculty development programs geared toward EMI started in 2010 with three different regional resource centers established (Tsui, 2017). Practice-wise, all lecturers of EMI courses are allowed to have a teaching assistant to help out by managing the class, or assisting the students to understand the course content (Dearden, 2014), as in the case introduced in this chapter. In addition, fulltime professors in the Department of Computer Science and Information Engineering (CSIE) of the university may choose to teach either three courses in Mandarin or two EMI courses to fulfil the teaching hours required for each semester. Even given these incentives, however, instructors in general still feel reluctant to offer EMI courses, one of the main reasons for which remains an inability to teach EMI courses effectively and with ease. It seems that not only students but also professors worry that their insufficient English proficiency may impede their experience with EMI.

The challenges of EMI are believed to reside in the mismatch between expected goals and actual implementation, which has been commonly acknowledged in the practices of Asian countries, for instance, as in tertiary education in Vietnam (Tu \& Burns, 2014). The macro level of the challenges, such as the social or political impacts, are not the main concern of this chapter; the EMI implementation in the area of information science will mainly be introduced at the micro level, which includes the classroom and the individual (Tsui \& Tollefson, 2004). Language issues, as mentioned already, will also be included in the discussion as a response to the choice of language medium in previous findings from EMI implementations in the engineering field, such as Basibek et al. (2014) and Dearden (2014). Specifically, in this chapter, the motivation and the design of a research methods and technical writing course for students of information engineering will be described. Discussion will focus on the integration between the main parts of the course content, as well as how the decision on which language to use is made in different areas of this course.

\section{Departmental EMI practices as per the university policy}

As mentioned already, EMI is a modern global trend in education, and Taiwan is no exception. The policy chosen by the Department of Computer Science and Information Engineering (CSIE) of the "highly prestigious academic institution in Taiwan" (Wu, 2006, p. 69), which will be introduced shortly, is indicative of EMI implementation in the field of information engineering.

The university's stated policy of internationalization has brought in more students from overseas. Thus, faculty members are encouraged by the department office to offer EMI courses. In this department, full-time CSIE professors have two alternatives: Each semester, they can teach either three courses in Mandarin, or two in English. In addition, the department offers 
each EMI course one teaching assistant to facilitate the progression of the course.

The seemingly lighter teaching load can be a double-edged sword for the faculty, though. Alleviation of the teaching load through offering EMI courses may be tempting, but in fact, few professors choose to take the offer. According to a professor from this department, only about 10 to $15 \%$ of the courses provided by the department are instructed in English. A main concern of the full-time faculty members is that most of them are not native speakers of English, and the same situation has also been encountered in EMI implementation in Korea (Kim, 2014). Specifically, teachers fear that their pronunciation or grammatical use of this foreign language might not be authentic, which may result in difficulties for students to fully understand the course content. This in turn, may lead to low scores in the end-of-semester student evaluation and eventually be detrimental to faculty members' promotion evaluations. For learners, the wide range of English proficiency levels among students presents another potential problem for EMI implementation. Some of the students may not be able to express themselves clearly in class, and the back-and-forth double checking between their actual language use and intentional meaning could waste time and energy.

A similar phenomenon has been observed in South Korea. As "the Korean government has been aggressively pursuing the internationalization of its universities" (Kim, 2014, p. 2), language has remained an issue to overcome for successful EMI implementations. This is partly because, compared with students in other fields such as humanities and social sciences, engineering students in general have lower English abilities, as shown via test scores or self-evaluation (Kim, 2014). Professors in the engineering field in Korea also felt that the students they taught had insufficient language skills for EMI implementation (Kang \& Park, 2004). Based on the professors' observations, over $40 \%$ of undergraduates and about $28 \%$ of graduate students did not have sufficient English abilities to join the EMI courses; however, the universities have not taken any corresponding steps to help the students (Kim, 2014).

In the department under discussion, the undergraduate students, like those in all the other departments of the same university, have to fulfill the English proficiency requirement before graduation. They have to pass the highintermediate level of the reading and the listening tests of the General English Proficiency Test (GEPT), which is equivalent to CEFR B2 level. For graduate students, however, there are no specific requirements for English proficiency, either from the university or from the department.

Under these circumstances, in order to meet the keen need of international exchange in academia nowadays, almost all professors in the CSIE department impose regulations on their advisees: In most laboratories, graduate students have to attend weekly group meetings, and the slides of their progress reports must be written in English, whereas the oral reports can be, and usually are, in Mandarin. In addition, students need to write their theses or dissertations in English. The effects of this are twofold. It is good training 
for English technical writing; moreover, it serves as a base for rewriting for future submissions to international conferences or journals after the students' graduation.

\section{TWRM: Historical development}

Technical Writing and Research Methods (TWRM) is a selective course jointly offered by the Department of CSIE and another graduate institute at the university related to networking and multimedia. Since TWRM is listed under the College of Electrical Engineering and Computer Science on the course website of the university, most of the students who have enrolled on the course are from this college. Specifically, students of previous TWRM classes were mainly from the Department of CSIE and the Department of Electrical Engineering, which constituted $70 \%$ and $30 \%$ of the total numbers, respectively.

The first TWRM class appeared in 2007, right after the professor who created the course started his career as an assistant professor at this university, and the course has been held regularly on a yearly basis ever since. The structure of the course has undergone a ten-year transformation process.

In the beginning, after observing the difficulty of the graduate students in writing up their work in English, the professor assumed that it must be a language problem - specifically, the students were not proficient enough in this foreign language to master technical writing. Therefore, the focus of the very first TWRM class aimed to improve students' English ability. However, at the end of the semester the professor realized that this was not the case: Though students did become more familiar with the vocabulary, grammar, and conventions of academic English, they were still unable to fluently express their thoughts in academic writing.

The focus was accordingly switched to writing skills when the course was held for the second time, yet the results were still not satisfactory. After several rounds of revision based on the students' feedback and the professor's reflections, the course frame has finally evolved into the current version.

Listed as one of the courses within the remit of the Professional English Writing for Academic Purposes offered by the Academic Writing Education Center (AWEC) of the university, the TWRM is provided with a trained instructor from the writing center. Aiming to equip the graduate students of the College of Electronic Engineering and Computer Science with the adequate knowledge and necessary skills to undertake their research, the concept of "team teaching" is applied to the course design of the current TWRM, as previous studies have shown that collaboration between the content and language experts facilitates the efficiency of EMI (Doiz et al., 2012).

Under the current semester system (two semesters for an academic year), the TWRM course lasts for eighteen weeks. The course comprises two main parts: research methods and technical writing. As it aims to impart the requisite skills to conduct research in the field of information science, the 
research method segment is taught by a professor from the Department of CSIE (the content instructor). Aiming to provide students with the ability to write up their own research findings, the technical writing segment is taught by a trained lecturer from the AWEC of the university (the language instructor).

\section{Design of TWRM}

Three features characterize the TWRM course. First, the schedule follows the procedure of conducting a research project; second, the implementation of the course serves as a perfect example of team teaching (Doiz et al., 2012), and third, translanguaging pedagogy (García \& Li, 2014) is effectively implemented. Each of these features will be discussed separately below.

\section{Sequencing of the core course components}

In the first class, the aims of the course are explained to the students, which include providing them with strategies to conduct quality research in the fields of information or electronic engineering and the skills to explain their findings. To achieve these goals, the students must first familiarize themselves with previous research findings and state-of-the-art knowledge of their fields via extensive reading, before selecting a topic for their research projects.

During the semester, about two thirds of the lectures are given by the content instructor and one third by the language instructor. The former mainly covers lectures on research-related issues, and the latter introduces students to the principles of academic writing and to hands-on strategies for writing technical papers. Both instructors prepare the course materials and visual aids in English, but deliver the lectures in Mandarin.

The schedule of the class basically follows the procedure of conducting a research project: Students first have to pick a research topic of a scale suitable for completion within one semester. Reminders and a detailed description of the execution of the research projects are all included, such as how experiments or surveys should be designed and conducted, as well as the subsequent evaluations and analyses. Alongside the lectures, students are required to give oral presentations or hand in writing assignments in accordance with the schedule.

It is in the very first class that the content instructor shares with the students the three key points that determine whether a submitted manuscript will be accepted for publication: research quality, writing skills, and language proficiency. The students are notified that only the former two are covered in the class since TWRM in itself is "not a language course."

\section{Teamwork in TWRM}

As has been discussed already, language proficiency plays a crucial role in determining the efficacy of EMI courses. According to the content instructor, 
students are responsible for catching up if their English proficiency is below par. Information about relevant resources on campus are also provided by the language instructor in the class for those who would like to strengthen their language skills outside the class. For instance, students may either take English courses held by the Language Center of the university (belonging to the College of Liberal Arts) or apply for free tutoring sessions from the Academic Writing Education Center on campus.

Despite the explicit disclaimer, the imbalance in English proficiency levels among students was a problem in previous TWRM courses, as no language screening mechanism had been set up for graduate students in the university, and students naturally varied in their English listening, speaking, reading, and writing skills. In order to solve this language issue, two strategies have been adopted, team teaching (Doiz et al., 2012) and translanguaging pedagogy (García \& Li, 2014).

As mentioned in a recent study, although EMI at the university level has become popular globally, research on integrating pedagogical guidelines to effectively implement an EMI course has been scarce. Some EMI teachers tend to avoid the language aspect, as if it were a weakness, but in fact, this can be solved by the concept of team teaching, the collaboration between language and content teachers (Lasagabaster, 2018). Specifically, in team teaching, the role of instruction shifts from an individual to a team, which also provides students with the opportunity to take a more active role in learning (Buckley, 1999). As team teaching is a field where more research remains to be done, in the following, the implementation details of the TWRM course will be described in order to share actual experience of interdisciplinary collaboration between a content field and the language realm.

In terms of the format of instruction, both lectures and discussion sessions are included in this course. General strategies for research methods, as well as oral presentation and technical writing skills are first introduced via lectures. The content instructor and the language instructor both use visual aids (mainly in the form of PowerPoint slides) to introduce the guidelines and information related to each topic, and there are accompanying in-class activities to help the students familiarize themselves with the concepts they have just learned. Topics of the lectures belong to three main categories: introduction to research ethics, techniques for conducting a research project, and practical skills such as tips in preparing slides for oral presentation and reminders for replying to reviewers' comments.

The lecture-driven format of instruction has in fact made the TWRM classes highly interactive. Students are encouraged to ask questions during the lectures. There is also a question-and-answer session after each lecture. Moreover, discussion sessions are included after each oral presentation session or in-class review of the writing assignments. Both the question-andanswer and the discussion sessions are in Mandarin. Quality of research and writing skills, rather than language details, are of the main concern in these discussions. 


\section{Research methods}

As already mentioned, the first half of the course focused on research methods, aiming for helping the students who have just begun their research career to establish the groundwork of their academic pursuit in the fields of information and electrical engineering. Topics such as research ethics and research methods, standard procedures and guidelines of conducting research in these fields were included, so were the details about experimental design and data analysis. The content instructor was responsible for the preparation of the class slides on these topics, and the language instructor helped him proofread the language use.

Training in research methods starts with a general introduction to the subfields and their state-of-the-art findings. Students then experience the entire research process compressed into the time frame of one semester, starting from topic selection and literature review, followed by methodology design and experiment execution, and culminating in paper writing.

For hands-on practice of research methods, the students are required to give individual oral presentations on topic selection, literature review, methods, and the experimental results of their individual projects, respectively. Each presentation usually lasts for six to eight minutes, depending on the size of the class that year. During the presentations, fellow students can give on-thespot feedback or comments via an online polling app. The content instructor usually gives concise comments, and helps answer the comments on the app immediately after the presentation. After all presentations are finished, the content instructor wraps up the discussion by indicating common errors and providing general suggestions. The language instructor, in turn, highlights students' erroneous English usages and corrects the English used in their slides and sends this feedback to the students after class. The final score for each presentation is averaged as the mean of the scores from the class (calculated using the online app), the content instructor, and the language instructor.

\section{Technical writing}

As the content of a research paper is covered by the content instructor in research methods, the language instructor mainly focuses on the hands-on skills of technical writing. The aim of this part is to equip students with basic tools for English writing, and to guide them through the process of putting together their research work in a section-by-section manner. It is hoped that by the end of the semester, the students will gain a clear picture of how an academic work is presented and also have a physical draft of their own work for future submission.

Starting from scratch, the language instructor first introduces the key concepts of English writing: the structure of English sentences and tips on organizing a paragraph. Concepts such as coherence and cohesion are also included, so that the students can use appropriate tactics to connect paragraphs 
and sections more smoothly, and eventually weave them altogether to form a complete draft of their research work.

Practical grammar issues, word choice, and tips on writing style are also introduced as part of the language content in order to sharpen students' "feel" for the language. The structure of relative clauses, for example, is explained. This is because of observations by the language instructor during in-class activities and from students' writing assignments in previous TWRM classes have revealed that restrictive and non-restrictive uses of this highfrequency structure tend to be mixed up by the students. In a similar vein, tense and aspect are also reviewed via short lectures followed by guided group discussions. Students are encouraged to share examples or counterexamples from real published research to verify the concepts and rules they have learned in class. Through repetitive operations of memory refreshing and concept reviewing of these details, the language instructor believes that the students in this class are able not only to enhance their sensitivity to the English language, but also to become familiar with well-written research works in their research fields.

To accumulate hands-on experience, students are asked to hand in their writing assignments in accordance with the course schedule - first the introduction, followed by methodology, results, and discussion sessions accordingly, and finally the abstract. The grading process is comprised of two steps, for which both the language instructor and the content instructor are responsible. First, the language instructor is responsible for checking the logic, grammar and language of the writing. The corrected files are then passed on to the content instructor, who checks whether the prerequisite knowledge and content expertise, be it in the information or electrical engineering field, are properly described. That is, while the language instructor concentrates on the structure and language of writing, the content instructor is responsible for monitoring the content expertise of the students' work.

Students in general, have found it helpful to have their writing assignments corrected by both of the instructors, as shown in the following piece of feedback from the end-of-semester evaluation of the Fall 2009 class:

I recommend that all graduate students at the College of Computer Science and Electrical Engineering take this course. Students can benefit a lot from its content, especially the assignments. There is seldom a chance to also have a language major correcting your writing in a course offered by the [CSIE] department. Please continue to offer the course.

\section{Language choices in TWRM}

One side effect of globalization is that English is replacing other languages as a primary medium of instruction, especially in higher education. Integrated learning methods like EMI are designed "to even better equip the learner with knowledge and skills suitable for the global age" (Marsh, 2006, p. 30). Now 
that English is the preferred language for presentation and publishing in academia (Li, 2012), and one of the goals of adopting EMI is to simultaneously sharpen language skills and pass on expert knowledge, the naïve thought is undoubtedly to assume English should be the only medium for EMI practice. However, based on Evans and Morrison (2011), even good English proficiency does not guarantee a painless learning experience in the EMI context, especially when students are used to communicating discipline-specific information in their first language. It is not surprising that previous studies have shown that in non-English speaking countries, a lack of ability among students and even instructors poses great challenges for EMI implementation (Doiz et al., 2012; Kim et al., 2017; Tu \& Burns, 2014). For example, Turkish instructors in the engineering field believed that their students were not proficient enough to learn subject knowledge via English, and supported the idea of delivering the courses in Turkish, their native language (Basibek et al., 2014).

In Taiwan, English is learned as the first "foreign" language, rather than an official or "daily" language, and thus it is natural for students to have varying English proficiency levels. To tackle this problem, it has been decided that a compromise must be made in language choice in order to improve the efficiency of EMI. That is, instead of adopting the original mode of Englishonly instruction, the medium language of the TWRM course should be more flexible, able to change according to the occasion. The employment of pedagogically planned translanguaging strategies perfectly fulfills this requirement (García \& Li, 2014).

Thus, unlike typical EMI courses, both English and Mandarin are used in TWRM. Mandarin is the native language of the two instructors and the majority of the students who take this course. The main reason for adopting a pedagogy of translanguaging was to allow for high-efficiency teaching under the time pressure imposed by the stipulation that both research methods and technical writing skills were to be covered in the class within one single semester. A bilingual mode has been adopted for the course and is adjusted in accordance with different scenarios in the class, details of which are shown in the following figure (Figure 3.1).

Class materials for the lectures on research methods are prepared in English, which usually include PowerPoint slides and accompanying handouts. The advantage of preparing materials about research methodology in English lies in the fact that most of the expertise and state-of-art findings in the fields of information and electrical engineering are published in this language, as mentioned in $\operatorname{Li}(2012$, p. 65):

English is now virtually the preferred language of natural sciences regardless of the scientists' language background, as shown in its preference in presenting and publishing research findings.

Thus, using the global language to prepare content knowledge for the course spares the cost of code switching, and gives the instructors and students a 


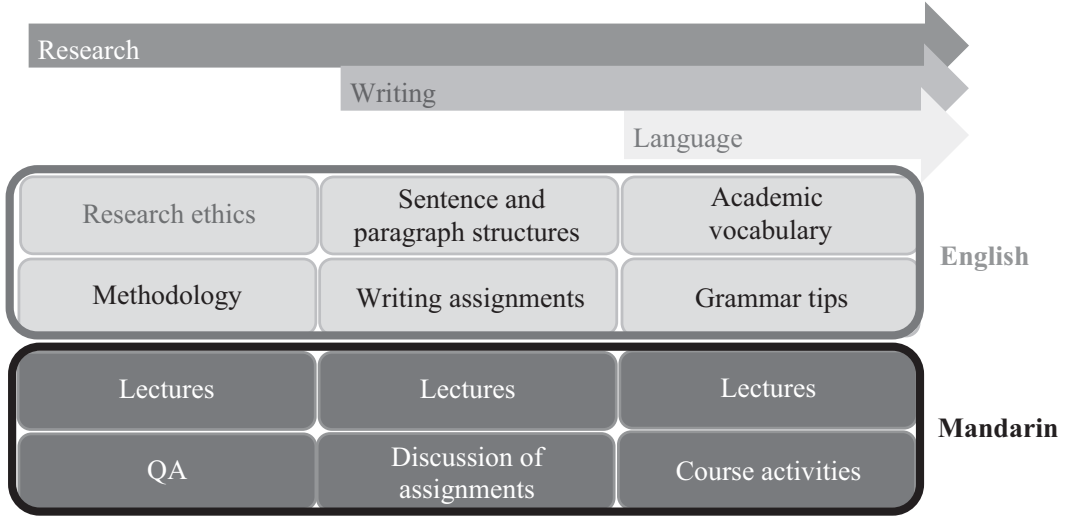

Figure 3.1 Course design and language choice of TWRM.

common platform for direct interaction using this lingua franca. In a similar vein, materials for technical writing skills are also written in English. After all, it is English writing skills that are to be taught - using the language itself for explication not only achieves for language consistency, but benefits from the convenience of providing authentic writing examples of appropriate language use.

In contrast, Mandarin is the choice for class delivery. Both instructors deliver their lectures in this language. Using their native language to explicate the content of the course materials (prepared in English) definitely facilitates students' understanding of the course content. Moreover, the rules or the formats for the assignments are less likely to be missed or misunderstood when they are expressed via L1. The same thought is followed in the comments on the students' presentations and in-class oral activities. The students feel it is easier to express themselves using their native language, which encourages them to share ideas in class. Lastly, the fact that teacherstudent interactions and peer discussions are held in Mandarin undoubtedly contributes to a much more enthusiastic class atmosphere in addition to a more efficient communication.

Thus, in terms of language choice, not much difference is observed between the content instructor and the language instructor in terms of material preparation and class delivery. The greatest divergence resides in the language of students' assignments: For oral presentations related to individual topics on research methods, the students have to prepare their slides in English, but they are free to choose either Mandarin or English for delivery. Writing assignments, in contrast, must be written in English, as one of the main goals of this course is to give the students the ability to independently write a paper for submission. 
In terms of correction, the content structure, grammatical use and word choice of students' presentation slides are checked by the language instructor after each presentation. Since the slides are prepared in English, the feedback is also given in the same language. Consistency of language choice is also found in the correction of the writing assignments: Suggestions for both the language part (the responsibility of the language instructor) and the content/ knowledge part (the responsibility of the content instructor) are provided in English.

Though there are no specific language rules for teacher-student interaction or peer discussion in class, Mandarin has turned out to be the natural choice for most occasions because it is the native language of the majority taking this course. However, the monolingual mode becomes bilingual when international students sign up for the class. Based on previous experiences, foreign students who are fluent in Mandarin always directly communicate with the instructors and their fellow classmates in Mandarin. Those who could barely understand Mandarin, on the other hand, would choose to ask questions and express themselves in English, and the instructors and their fellow classmates would reply in English.

\section{Discussion}

Globalization has made EMI a trend in tertiary education all over the world, and Taiwan is no exception. However, despite the support and encouragement from the Ministry of Education, most professors still feel reluctant to offer EMI classes. English proficiency has been a main concern, be it from the faculty or from students. Most of the full-time faculty members in Taiwan are not native speakers of English, and it is natural they would worry that their pronunciation or language use might not be correct, which might negatively influence students' comprehension of the course content. In addition, the wide range in students' English proficiency levels further complicates the situation and increases the difficulty in implementing EMI courses. It is believed that, when compared with South Korea where engineering students in general have lower English abilities than those in other fields and whose universities do not propose any solutions to help the students (Kim, 2014), the graduate students in the Department of CSIE at this top ranking university in northern Taiwan possess better English listening comprehension skills, since most Taiwanese universities have instituted minimum thresholds for the graduation of the undergraduates. In addition, the university does provide a supportive system of language courses to strengthen students' English ability, as well as writing consultation sessions to help them revise their work. This is different from the cases of Japan and Korea, in which the lack of institutional support is commonly noted in EMI practice (Chapple, 2015; Kim, 2014), and to some extent, this support compensates for the varying levels of English proficiency that students on the TWRM course possess. 
As mentioned, three features characterize the TWRM course. Firstly, scheduling the course based on the procedure of a typical information science research project provides students with a clear picture of the time sequence: How a study in this field should be brainstormed, designed, and executed. With this experience of starting from scratch, students are felt to be more confident conducting the larger-scaled research projects required for their theses later on.

Secondly, to adapt to the imbalance in English ability among the students enrolling in the class, a compromise has been made in the language choice of this EMI course - instead of adopting an English-only instruction mode, the concept of translanguaging has been incorporated into the design and implementation of the TWRM. Translanguaging-informed EMI programs may have different combinations of language use. For example, the input text can be entirely in English, with visual aids provided in the students' first language, or with the key concepts translated into the first language orally by the instructor. Alternatively, the input text can also be in the students' native language to ensure comprehension, with only key terms translated into English (Barnard, 2014). In TWRM, the medium language is task-oriented. For both instructors, English is used for course material preparation and the correction of writing assignments; for the students, it is used in the content of the assignments and in the visual aids used in their presentations. Mandarin, on the other hand, is the choice for class delivery, discussion, and class interaction. This decision allows both the instructors and the students to reduce the cost of code switching in receiving state-of-the-art knowledge and to simultaneously maintain efficient communication. Moreover, including the learners' native language into EMI teaching not only alleviates the negative impact of varying English proficiency levels from the students, but nurtures a positive class atmosphere of eager attention and active discussion. For example, written feedback from end-of-semester evaluations of the class of 2012 shows that students felt the instructors in general had guided them through the whole course in a systematic but easy-going and humorous way.

Lastly, the integration of the pedagogical strategy of "team teaching" (Doiz et al., 2012) into the course design also facilitated the effective implementation of TWRM. Traditionally, the two parts of team teaching in EMI refer to the content knowledge and English ability; however, in TWRM, rather than a clear distinction between content knowledge vs. the English language, the integration is between two domains of expertise: research methodology in the information and electrical engineering fields, and technical writing skills in academic English. The content and language instructors are each responsible for their respective domain. During the semester, they support each other in the design and execution of the course, helping each other out from time to time. For example, the language instructor might help the content instructor check the grammar and language use of the lecture slides before class delivery, and the content instructor might also supplement particular tense or modality preferences in English writing alongside the instruction of a certain section in 
research methods. The smooth flow of the TWRM classes over the past years demonstrates a successful experience of this cross-field collaboration.

The end-of-semester questionnaire-based evaluations show that students who took the TWRM courses found the above characteristics of the course design helpful. Observing the collaboration of the two instructors from different fields, the students implicitly learned that conducting research and writing it up in academic English are two separate skills, both of which are equally critical and can be properly facilitated by appropriate training.

A good course! A good course! A good course!

(Class of Fall 2011)

Very useful in terms of both doing research and writing.

(Class of Fall 2011)

I would like to express my gratitude for the teachers' guidance. In this class, I learned how to do research and how to write appropriately in academic English, to which I had not paid attention before... This is by far the most practical course I have ever taken. It is definitely a course worth taking!

(Class of Fall 2012)

I have learned a lot from this course. I started to pay attention to the details about technical writing, and strongly believed that there is a lot more to learn. The way the instructors arranged the course content was clear, and it was easy for students to follow. It was a very good experience in taking such a course.

(Class of Fall 2013)

This is one of the best quality classes I have ever taken.

(Class of Fall 2014)

I was satisfied with the design of the course... In my opinion, it is efficient to learn this way. I am grateful for the teachers' guidance. Their opinions were very helpful, which contributed to my better understanding about doing research, and I look forward to completing a project on my own in the near future.

(Class of Spring 2018)

It has been a long time since my last time taking an English[-related] course. In this class skills of technical writing and research methods were taught, which helped me a lot on conducting a research project and writing it up in an academic way. The class was small in size, and thus there were more interactions between the instructors and the students.

(Class of Fall 2018) 
Putting everything together, the TWRM should not be considered an ESP or EAP course, but rather a modified version of an EMI course. In an ESP or EAP course, language is always the main concern. Both the teacher and the students aim at acquiring the terminology and communication skills required for a certain discipline. This is different from an EMI course, since a connection between the language itself and high levels of knowledge in the relevant academic field is always to be expected (Shohamy, 2012).

One may argue that research methods do not involve "high levels" of knowledge in information engineering. In fact, it should be born in mind that those who enrolled in the TWRM classes had to conduct a research project of their own. As the students were either from the master or PhD programs in this field, the level of their studies is by no means be low. In the TWRM classes, although the native language of the instructors and most of the students is included in order to facilitate communication orally, English is nevertheless the main medium for class materials and sharing of research findings. All in all, with the inclusion of the training of academic writing skills and the use of English as a tool to explore and communicate expert knowledge in information engineering, the TWRM course should be categorized as one in the EMI realm.

Moreover, as scheduling of the TWRM is based on the procedure of a typical research project in information science, other courses in this field may follow the course design for EMI implementation, especially introductory ones where lecturing is adopted as the main format. For example, in courses like Introduction to Human-Computer Interaction and Design or Introduction to Digital Image Processing, the integration of expert knowledge and technical writing as delivered in the form of team teaching should serve as a good platform for effective learning and boost the pace of publication. This is because both the fundamental concepts and the techniques of academic writing are included in the same course, and thus students are guided through the complete process from the brainstorming of research ideas to the final report on their research work. In addition, the flexible combination of English and Mandarin in discursive practices not only provides a chance for the students to become more familiar with the use of the global language in their fields of expertise but ensures that they will not shy away from asking questions or taking part in discussion sessions during the class.

Though absent from TWRM, one very last thing worth noticing is that as mentioned in earlier sections, both the instructors and the students of EMI classes in higher education may face difficulties in preparing or taking the course due to their English proficiency level. Recently, in Taiwan, teacher development programs have been established to offer non-native Englishspeaking EMI teachers a chance to sharpen their language and pedagogical skills (Tsui, 2017). At the same time, additional supplementary resources like EAP courses, also serve as a way to enhance the academic ability of students who seem to lag behind so that they can better adapt to EMI classes (Huang, 2012). 


\section{Concluding remarks}

EMI indeed provides a good opportunity to simultaneously learn both the content knowledge and the foreign language for learners from the countries where English is not a national language; however, corresponding details have to be carefully planned before real implementation. In the case of TWRM, the adoption of "team teaching" and a more flexible choice of the medium languages have contributed to a successful adaptive EMI implementation in the field of information engineering. Team teaching integrated expertise on research methods and technical writing in this course, during which each student conducted a real research project by following a step-by-step procedure. Moreover, both instructors and students benefited from the task-oriented translanguaging pedagogy. Higher efficiency and more engaged class atmosphere were achieved through the incorporation of their native language into the implementation of TWRM.

\section{References}

Barnard, R. (2014). English medium instruction in Asian universities: Some concerns and a suggested approach to dual-medium instruction. Indonesian Journal of Applied Linguistics, 4(1), 10-22.

Basibek, N., Dolmaci, M., Cengiz, B. C., Bur, B., Dilek, Y., \& Kara, B. (2014). Lecturers' perceptions of English medium instruction at engineering departments of higher education: A study on partial English medium instruction at some state universities in Turkey. Procedia-Social and Behavioral Sciences, 116, 1819-1825.

Buckley, F. J. (1999). Team teaching: What, why, and how? Thousand Oaks, CA: Sage Publications.

Chapple, J. (2015). Teaching in English is not necessarily the teaching of English. International Education Studies, 8(3), 1-13.

Cheremissina, I. A., \& Riemer, M. J. (2001). English for specific purposes in engineering education at the Tomsk Polytechnic University. In Z. J. Pudlowski \& R. Cwilewicz (Eds.), Proceedings of the 5 th Baltic region seminar on engineering education (pp. 57-60). Clayton, Australia: Monash Asia Institute.

Dearden, J. (2014). English as a medium of instruction - A growing global phenomenon. British Council. Retrieved from www.britishcouncil.es/sites/default/files/british_ council_english_as_a_medium_of_instruction.pdf

Doiz, A., Lasagabaster, D., \& Sierra, J. M. (2012). Future challenges for Englishmedium instruction at the tertiary level. In A. Doiz, D. Lasagabaster, \& J. M. Sierra (Eds.), English-medium instruction at universities: Global challenges (pp. 213-221). Bristol, UK: Multilingual Matters.

Evans, S., \& Morrison, B. (2011). Meeting the challenges of English-medium higher education: The first-year experience in Hong Kong. English for Specific Purposes, 30, 198-208.

García, O. (2009). Bilingual education in the 21st century: A global perspective. Chichester, UK: Wiley-Blackwell.

García, O., \& Li, W. (2014). Translanguaging: Language, bilingualism and education. New York: Palgrave Macmillan. 
Huang, D. F. (2015). Exploring and assessing effectiveness of English medium instruction courses: The students' perspectives. Procedia-Social and Behavioral Sciences, 173, 71-78.

Huang, Y. P. (2012). Design and implementation of English-medium courses in higher education in Taiwan: A qualitative case study. English Teaching and Learning, 36(1), 1-51.

Hüttner, J. (2019). Occupying a new space: Oral language skills within the disciplines in English-medium instruction. In B. Loranc-Paszylk (Ed.), Rethinking directions in language learning and teaching at university level (pp. 5-26). Research-publishing. net. doi:10.14705/rpnet.2019.31.889

Kang, S. Y., \& Park, H. S. (2004). Instructor beliefs and attitudes about English medium instruction: Report of questionnaire study. Journal of Engineering Education Research, 7(1), 87-96.

Kim, E. G. (2014). Korean engineering professors' views on English language education in relation to English-medium instruction. The Journal of Asia TEFL, 11(2), 1-33.

Kim, E. G., Kweon, S. O., \& Kim, J. (2017). Korean engineering students' perceptions of English-medium instruction (EMI) and L1 use in EMI classes. Journal of Multilingual and Multicultural Development, 38(2), 130-145.

Lasagabaster, D. (2018). Fostering team teaching: Mapping out a research agenda for English-medium instruction at university level. Language Teaching, 51(3), 400-416.

Li, D. C. S. (2012). Linguistic hegemony or linguistic capital? Internationalization and English-medium instruction at the Chinese University of Hong Kong. In A. Doiz, D. Lasagabaster, \& J. M. Sierra (Eds.), English-medium instruction at universities: Global challenges (pp. 65-83). Bristol, UK: Multilingual Matters.

Macaro, E. Curle, S., Pun, J., An, J, \& Dearden, J. (2018). A systematic review of English medium instruction in higher education. Language Teaching, 51(1), 36-76.

Marsh, D. (2006). English as medium of instruction in the new global linguistic order: Global characteristics, local consequences. In S. M. Stewart, J. E. Olearski, $\&$ D. Thompson (Eds.), Proceedings of the second annual conference for Middle East teachers of science, mathematics and computing (pp. 29-38). Abu Dhabi, United Arab Emirates: METSMaC.

Shohamy, E. (2012). A critical perspective on the use of English as a medium of instruction at universities. In A. Doiz, D. Lasagabaster, \& J. M. Sierra (Eds.), English-medium instruction at universities: Global challenges (pp. 196-210). Bristol, UK: Multilingual Matters.

Tsui, A. B. M., \& Tollefson, J. W. (2004). The centrality of medium-of-instruction policy in sociopolitical processes. In J. W. Tollefson \& A. B. M. Tsui (Eds.), Medium of instruction policies: Which agenda? Whose agenda? (pp. 1-18). London: Lawrence Erlbaum Associates.

Tsui, C. (2017). EMI teacher development programs in Taiwan. In W. Tsou \& S.-M. Kao (Eds.), English as a medium of instruction in higher education: Implementations and classroom practices in Taiwan (pp. 165-182). Singapore: Springer.

Tu, N. T. T., \& Burns, A. (2014). English as a medium of instruction: Challenges for Vietnamese tertiary lecturers. The Journal of Asia TEFL, 11(3), 1-31.

Wilkinson, R. (2013). English-medium instruction at a Dutch university: Challenges and pitfalls. In A. Doiz, D. Lasagabaster, \& J. M. Sierra (Eds.), English-medium instruction at universities: Global Challenges (pp. 3-24). Bristol, UK: Multilingual Matters. 
60 Sally Chen and Shou-De Lin

Wu, W. (2006). Students' attitudes toward EMI: Using Chung Hua University as an example. Journal of Education and Foreign Language and Literature, 5(4), 67-84.

Yang, W. (2015). Content and language integrated learning next in Asia: Evidence of learners' achievement in CLIL education from a Taiwan tertiary degree programme. International Journal of Bilingual Education and Bilingualism, 18(4), 361-382. 